\title{
Questões ambientais e a importância da educação em ciências para o empoderamento de indígenas da Amazônia
}

Environmental issues and the importance of science education for the empowerment of indigenous people in the Amazon

Cuestiones ambientales y la importância de la educación en ciencias para el empoderamiento de los pueblos indígenas de la Amazonía

Recebido: 23/12/2020 | Revisado: 25/12/2020 | Aceito: 29/12/2020 | Publicado: 03/01/2021

Reginaldo de Oliveira Nunes
ORCID: https://orcid.org/0000-0003-4287-9036
Universidade Federal de Rondônia, Brasil
E-mail: reginaldonunes@ unir.br
Pedro Guilherme Rocha dos Reis
ORCID: https://orcid.org/0000-0002-9549-2516
Universidade de Lisboa, Portugal
E-mail: preis@ie.ulisboa.pt
Iuri da Cruz Oliveira
ORCID: https://orcid.org/0000-0003-2396-0541
Instituto Federal de Educação, Ciência e Tecnologia de Rondônia, Brasil
E-mail: iuricruzmpf@gmail.com

\section{Resumo}

Este trabalho objetivou compreender como os problemas ambientais podem ser trabalhados na educação em ciências nas escolas indígenas, por meio de uma reflexão dos próprios indígenas. Foram aplicados questionários compostos por nove questões abertas, envolvendo dados sobre os problemas ambientais e o ensino de ciências nas escolas indígenas. Participaram da pesquisa cento e doze estudantes indígenas em formação do curso de Licenciatura em Educação Intercultural, da Universidade Federal de Rondônia. Os resultados indicam que a perda da floresta é fator marcante em relação aos fatores ambientais, envolvendo queimadas, extração ilegal de madeiras e o desmatamento. Esses fatores são motivados pela ambição e ganância do homem. Em relação aos problemas ambientais, $84,8 \%$ acreditam que podem ser trabalhados no currículo da escola, especificamente nas disciplinas de ciências e biologia $(29,8 \%)$. As temáticas abordadas na escola se referem aos fatores que afetam o meio ambiente e quando foram trabalhadas envolveram diferentes estratégias de ensino. Considera-se que é possível, por meio de planejamento e da formação de novos professores indígenas, que essas visões sobre os problemas ambientais possam refletir no currículo de ciências das escolas indígenas, tornando-se fatores essenciais na busca da autonomia e afirmação da identidade cultural.

Palavras-chave: Indígenas; Educação em ciências; Questões ambientais.

\begin{abstract}
This work aimed to understand how environmental problems can be worked on in Science education in indigenous schools, through a reflection of the indigenous themselves. Questionnaires were applied consisting of nine open-ended questions, involving data on environmental problems and Science teaching in indigenous schools. One hundred and twelve indigenous students in the formation of the Degree in Intercultural Education at the Federal University of Rondônia participated in the survey. The results indicate that the loss of the fores tis a striking fator in relation to environmental factors, involving burning, illegal timber extraction and deforestation. These factors are motivated by man's ambition and greed. In relation to environmental problems, $84.8 \%$ believe that they can be worked on in the school curriculum, specifically in the subjects of science and biology (29.8\%). The themes addressed in school refer to factors that affect the environment and when they were worked on involved different teaching strategies. It is considered that it is possible, through planning and the formation of new indigenous teachers, that these views on environmental problems can be reflected in the science curriculum of indigenous schools, becoming essential factors in the search for autonomy and affirmation of cultural identity.
\end{abstract}

Keywords: Indigenous; Education in sciences; Environmental issues.

\section{Resumen}

Este trabajo tenía como objetivo entender cómo se pueden trabajar los problemas ambientales en la educación científica en las escuelas indígenas, a través de una reflexión de los propios indígenas. Se aplicaron cuestionarios que consistían en nueve preguntas abiertas, con datos sobre problemas ambientales y la enseñanza de las ciencias en las 
escuelas indígenas. Participaron en la encuesta ciento doce estudiantes indígenas en formación para el curso de licenciatura en Educación Intercultural de la Universidad Federal de Rondonia. Los resultados indican que la pérdida del bosque es un factor llamativo en relación con los factores ambientales, que implica la quema, la extracción ilegal de madera y la deforestación. Estos factores están motivados por la ambición y la codicia del hombre. En relación con los problemas ambientales, el $84,8 \%$ cree que se pueden trabajar en el programa escolar, específicamente en las asignaturas de ciencias y biología $(29,8 \%)$. Los temas abordados en la escuela se refieren a los factores que afectan al medio ambiente y cuando se trabajaron, implicaron diferentes estrategias de enseñanza. Se considera que es posible, mediante la planificación y la formación de nuevos maestros indígenas, que estas opiniones sobre los problemas ambientales se reflejen en el programa de estudios de ciencias de las escuelas indígenas, convirtiéndose en factores esenciales en la búsqueda de la autonomía y la afirmación de la identidad cultural.

Palabras clave: Indígena; Educación em ciencias; Cuestiones ambientales.

\section{Introdução}

Entre os problemas da atualidade, as questões ambientais ganham destaque em função de rápidas transformações devido as ações antrópicas, associadas ao aumento da chamada demanda, por recursos naturais. Em consequência, há um aumento nos conflitos de utilização da terra, a degradação dos recursos ambientais, motivados por práticas de manejo inadequadas (Nascimento et al., 2006). Essa realidade, é evidente nas terras indígenas, a exemplo do que ocorre na Amazônia, onde os problemas ambientais intervenientes à sua conservação refletem sobre o histórico de ocupação econômica da região onde as terras indígenas estão inseridas (Soares \& Pereira, 2015).

Essas terras indígenas compreendem aproximadamente $12 \%$ do território nacional, sendo quase sua totalidade composta de ecossistemas, possivelmente conservados, ao qual abrigam expressiva biodiversidade, especialmente no cerrado e na floresta amazônica. Assim, as terras indígenas têm uma função ambiental a cumprir, ou seja, é necessário garantir vida digna aos povos indígenas, respeitando seus costumes e tradições e preservando a biodiversidade existente (Abi-Eçab, 2011).

Contrariamente, os direitos estabelecidos na Constituição Federal como necessários à preservação do patrimônio cultural imaterial indígena, o direito a sobrevivência tanto física quanto cultural e a conservação da biodiversidade e equilíbrio ambiental entram em contraste com a globalização e deculturação, que alteram os modos de vida, implicando a adoção de práticas não sustentáveis vinculado a pressões políticas e econômicas e relacionadas ao aumento da área de plantio, demanda por geração de energia, extração de minérios, entre outros problemas (Abi-Eçab, 2011).

Segundo Carneiro Filho (2009), as terras indígenas são de fundamental importância ao se levar em conta a proteção dos direitos e da cultura dos indígenas e a conservação da floresta. Também são responsáveis pelo abastecimento de variados tipos de produtos nas cidades, entretanto, muitas terras indígenas, tem sido invadida por grileiros, madeireiros, fazendeiros, garimpeiros, pescadores e caçadores, cujo único interesse é a busca pelos recursos naturais e sua exploração ilegal.

Observa-se que segmentos conservadores do governo e da imprensa, líderes ligados ao agronegócio, do setor hidrelétrico, parlamentares de variados vieses ideológicos se empenham em repassar à sociedade uma ideia de que a criação de áreas protegidas, como as terras indígenas, é uma ameaça ao crescimento e desenvolvimento econômico do país. Neste caso, os povos indígenas que defendem seus direitos são apresentados como os vilões do "desenvolvimento".

Nesse sentido, é importante destacar de que forma a Educação em Ciências poderia contribuir ao empoderamento de alunos e professores visando a resolução dos problemas ambientais que atingem a maioria das terras indígenas localizadas na Amazônia. A capacitação para a ação sociopolítica por meio da educação é uma dessas maneiras.

Entende-se por ação sociopolítica, as "práticas educativas fortemente centradas nos alunos e nos problemas que eles considerem interessantes e socialmente relevantes" (Reis, 2013). Segundo Hodson (1998), a ação comunitária baseada na investigação é frequentemente considerada uma dimensão importante da alfabetização científica, sendo também uma "forma de capacitar (empoderar) os alunos como críticos e construtores de conhecimento" (Bencze \& Sperling, 2012). 
Portanto, os professores indígenas que foram os percursores do trabalho, assumirão o papel de construtores de um currículo de ciências que auxilie na tomada de decisão sobre os problemas ambientais de seus territórios indígenas. A partir desse currículo, é importante que os mesmos possam estabelecer medidas conjuntas (professores, alunos e comunidade) para o empoderamento de seu território, visando consequentemente, a qualidade de vida de todos que nele vivem.

A discussão em questão, baseada em questões socioambientais, citadas por Reis (1997, 2004, 2013), poderá contribuir para que os alunos e professores indígenas participem em debates e processos de tomadas de decisão, contribuindo para uma construção de uma sociedade mais democrática onde todos tenham vez e voz. O envolvimento de alunos em iniciativas de ativismo coletivo sobre questões de interesse ambiental, direcionado pela investigação e pesquisa, proporciona o aumento de seu conhecimento acerca dos problemas e desenvolve competências de investigação e cidadania participativa e fundamentada (Reis, 2013).

Procura-se, então, compreender como os problemas ambientais podem ser trabalhados no ensino de ciências nas escolas indígenas, a partir de uma reflexão dos próprios indígenas, visando o empoderamento de seus povos, e, consequentemente, a luta por seus direitos, no que se refere aos fatores ambientais.

\section{Metodologia}

Os objetivos do estudo estão relacionados a realização do levantamento de dados sobre os problemas ambientais na perspectiva dos estudantes indígenas em formação no estado de Rondônia, na reflexão em relação a maneira como o ensino de ciências pode favorecer na resolução dos problemas, bem como na capacitação para a ação sociopolítica por meio da educação nas escolas indígenas.

A pesquisa, classificada como interpretativa, com a utilização de abordagem qualitativa (Pereira et al., 2018), tendo em vista o conhecimento mais aprofundado da realidade dos povos indígenas da Amazônia e a definição de projetos que possam contribuir para o seu empoderamento como cidadãos. Procedeu-se ao cálculo de estatística descritiva com o objetivo de detectar grandes tendências nos dados qualitativos recolhidos.

Para atingir os objetivos propostos, foi construído um questionário, composto por nove questões abertas, envolvendo os problemas ambientais (quais problemas afetam as terras indígenas, a aldeia, as causas, responsáveis e o que poderia ser feito para minimizar ou resolver tais problemas), e os problemas ambientais e a relação com a escola (se os problemas são abordados no currículo da escola, se já foi trabalhado na escola, como futuro professor como poderia trabalhar esses problemas e de que forma a escola poderia contribuir na resolução dos problemas que afetam os povos indígenas).

O desenho da pesquisa levou em consideração a coleta, mensuração e análise dos dados. A amostragem foi por conveniência ou voluntária, sendo incluídos na pesquisa todos os alunos regularmente matriculados no curso e como critérios de exclusão, os que não quiseram participar ou que não estavam presentes no momento da aplicação do questionário.

Participaram da pesquisa 112 estudantes indígenas em formação no Curso de Licenciatura em Educação Básica Intercultural, da Universidade Federal de Rondônia, no campus de Ji-Paraná. Os participantes pertencem a 27 etnias indígenas, residentes de 21 terras indígenas (Figura 1), localizadas no estado de Rondônia, Acre e Mato Grosso. Das 21 terras indígenas a que pertencem os participantes da pesquisa, 19 são regularizadas, uma está em estudo (T.I. Poruborá), e uma em análise para regularização (T.I. Porto Murtinho).

As etnias mais representativas foram Suruí (15,2\%), seguido de Wari' (10,7\%), Arara e Karitina (9,8\% cada), Zoró $(8,9 \%)$, entre outras, conforme pode ser visualizado na Figura 2. 
Figura 1 - Número de participantes da pesquisa por terra indígena. Ji-Paraná, Rondônia, 2019.

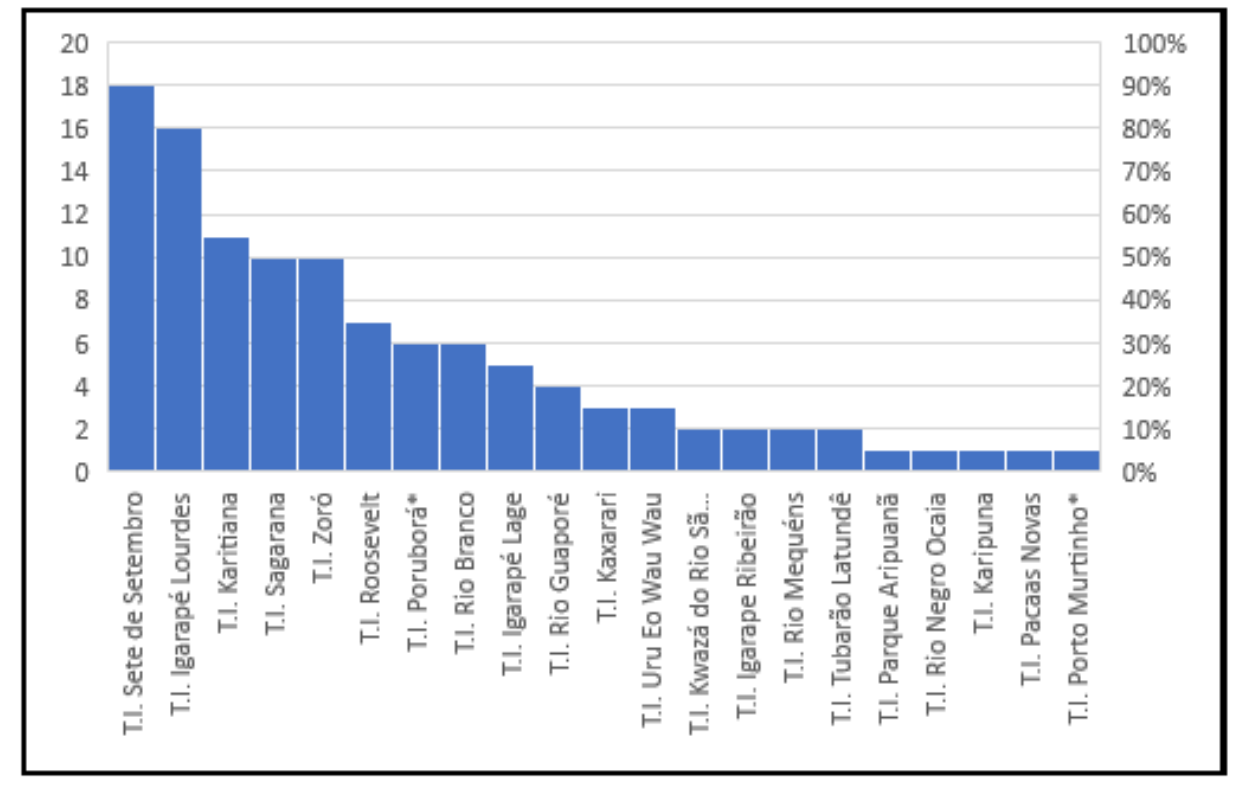

Fonte: Dados da pesquisa (2019).

Figura 2 - Número de participantes da pesquisa por etnias indígenas. Ji-Paraná, Rondônia, 2019.

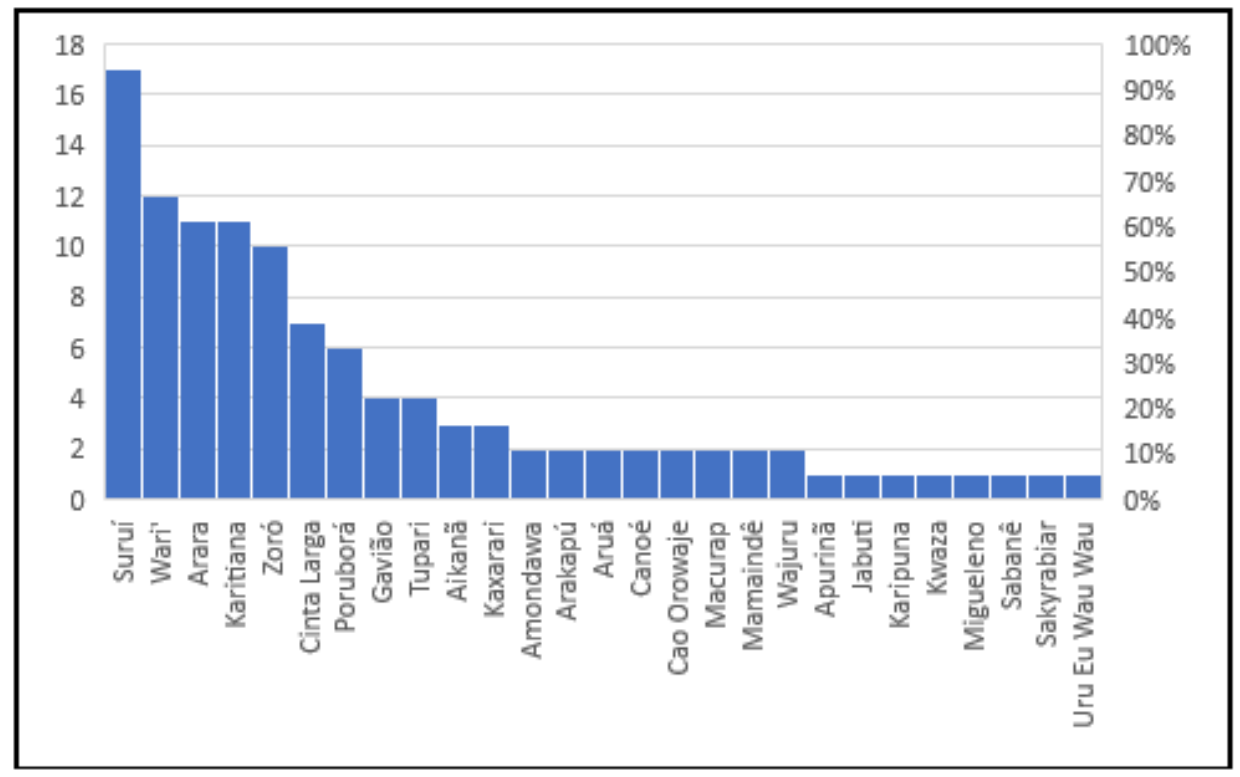

Fonte: Dados da pesquisa (2019).

No que se refere ao gênero dos entrevistados, $66,1 \%$ são do sexo feminino e 33,9\% do sexo masculino, provenientes da faixa etária compreendida entre os 25 a 29 anos (27,7\%), seguido de 30 a 34 anos (24,1\%), 20 a 24 anos (21,4\%), 35 a 39 anos (14,3\%), 40 a $44 \operatorname{anos}(9,8 \%), 45$ a 49 anos (0,9\%) e não informou a idade (1,8\%). Quanto ao estado civil, 44,6\% são solteiros, $26,8 \%$ casados, $19,6 \%$ vivem em união estável, $0,9 \%$ divorciados e $8,0 \%$ não responderam.

Levando em consideração os aspectos éticos da pesquisa científica, o projeto foi aprovado pela Comissão de Ética do Instituto de Educação da Universidade de Lisboa, sob o número de registro 3802, em 16 de outubro de 2019. 


\section{Resultados e Discussão}

Em relação a atuação como professor na escola indígena, 49,1\% dos participantes da pesquisa são professores nas escolas indígenas e 50,9\% ainda não atuam como professores, no entanto, são estudantes de um curso de formação de professores visando assumir o protagonismo das atividades docentes nas escolas em suas aldeias.

Dos $49,1 \%$ que atuam como professores nas escolas indígenas, 27,3\% exercem a função entre 1 e 2 anos, 20,0\% entre 3 e 4 anos, 18,2\% entre 7 e 8 anos, 14,5\% entre 5 e 6 anos, 12,7\% a mais de 10 anos e 7,3\% entre 9 e 10 anos. Da parcela que não atua como professores, 77,2\% são estudantes, seguido de agricultores (8,8\%), membro da comunidade, agente indígena de saúde e assistente administrativo (3,5\% cada), dona de casa e funcionário público (1,8\% cada).

Devido grande parte dos participantes da pesquisa serem professores, a principal fonte de renda é proveniente dos salários recebidos $(50,9 \%)$, seguido da agricultura (25,0\%), do salário de um dos membros da família (5,4\%), da venda de artesanato $(4,5 \%)$, do recebimento de bolsa família $(2,7 \%)$, proveniente da coleta e comercialização da castanha $(2,7 \%)$ e $8,9 \%$ não responderam a questão. Essa fonte de renda é responsável pelo sustento de suas famílias, que variam entre uma a mais de 8 pessoas residentes nas casas. A maior parte das famílias é composta de 5 a 6 pessoas (39,3\%), de 3 a 4 pessoas (36,6\%), de 7 a 8 pessoas $(17,9 \%)$, de 1 a 2 pessoas $(4,5 \%)$, e mais de 8 pessoas $(1,8 \%)$.

Observa-se que a profissionalização docente é fator primordial a sustentabilidade financeira nas aldeias, já que representa uma fonte de renda que auxilia na sobrevivência do professor indígena e dos integrantes de sua família (esposa (o) e filhos). Além do aspecto financeiro, representa também assumir o protagonismo da educação indígena, que muitas vezes, estava restrita a professores não indígenas, com pouco ou sem nenhum conhecimento sobre a cultura indígena.

\subsection{Os problemas ambientais na visão dos participantes da pesquisa}

Visando compreender os problemas ambientais que acontecem nas terras indígenas, foram realizados cinco questionamentos, sendo eles: Que problemas ambientais afetam as terras indígenas? Quais os problemas ambientais que ocorrem na sua aldeia? Por que esses problemas ambientais acontecem? Quem são os responsáveis por esses problemas ambientais? Na sua opinião, o que poderia fazer para diminuir ou resolver esses problemas?

Em relação aos problemas ambientais que acontecem nas terras indígenas e nas aldeias dos participantes da pesquisa, os mais representativos foram desmatamento (20,1\% na aldeia e $18,0 \%$ nas terras indígenas em geral), conforme pode ser observado na Tabela 1. 
Tabela 1 - Percepção dos participantes da pesquisa em relação aos problemas ambientais que afetam as terras indígenas em geral e nas suas terras indígenas. Ji-Paraná, Rondônia, 2019.

\begin{tabular}{|c|c|c|c|}
\hline \multicolumn{2}{|c|}{$\begin{array}{l}\text { Problemas Ambientais - Terras Indígenas } \\
\text { em geral }\end{array}$} & \multicolumn{2}{|c|}{$\begin{array}{l}\text { Problemas Ambientais - Aldeias dos } \\
\text { Participantes da Pesquisa }\end{array}$} \\
\hline Problema & Freq. & Problema & Freq. \\
\hline Queimadas & $15,5 \%$ & Queimadas & $18,9 \%$ \\
\hline Extração ilegal de madeiras & $15,8 \%$ & Extração ilegal de madeiras & $15,3 \%$ \\
\hline- & - & Extração consentida de madeiras & $1,2 \%$ \\
\hline Desmatamento & $18,0 \%$ & Desmatamento & $20,1 \%$ \\
\hline Extração ilegal de minérios & $11,5 \%$ & Extração ilegal de minérios & $6,4 \%$ \\
\hline $\begin{array}{l}\text { Agronegócio } \quad \text { (pecuária } \\
\text { agricultura) }\end{array}$ & $3,7 \%$ & $\begin{array}{l}\text { Agronegócio } \quad \text { (pecuária } \\
\text { agricultura) }\end{array}$ & $2,8 \%$ \\
\hline Caça e Pesca ilegal & $5,3 \%$ & Caça e Pesca ilegal & $7,6 \%$ \\
\hline Perda do território & $5,9 \%$ & Perda do território & $2,0 \%$ \\
\hline Poluição & 16,4 & Poluição & $19,7 \%$ \\
\hline $\begin{array}{l}\text { Problemas ambientais com os rios } \\
\text { (construção de } \\
\text { assoreamento) }\end{array}$ & $5,3 \%$ & $\begin{array}{l}\text { Problemas ambientais com os rios } \\
\text { (construção de barragens, oscilação } \\
\text { dos níveis de água, secas, } \\
\text { assoreamento, erosão) }\end{array}$ & $3,6 \%$ \\
\hline $\begin{array}{l}\text { Problemas ambientais com animais } \\
\text { (extinção de espécies) }\end{array}$ & $0,6 \%$ & $\begin{array}{l}\text { Problemas ambientais com animais } \\
\text { (diminuição de peixes, extinção de } \\
\text { espécies, interferência no ciclo } \\
\text { reprodutivo de quelônios e peixes) }\end{array}$ & $2,4 \%$ \\
\hline $\begin{array}{l}\text { Problemas com o ambiente } \\
\text { (degradação, diminuição dos } \\
\text { recursos naturais, grandes projetos } \\
\text { de interesse político } \\
\text { internacional) }\end{array}$ & $2,2 \%$ & 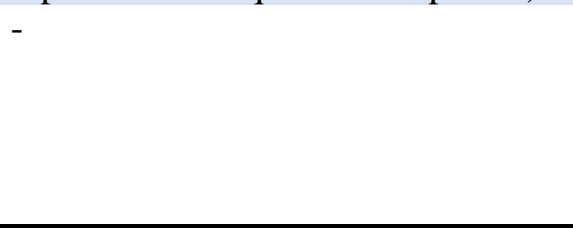 & - \\
\hline & $100 \%$ & & $100 \%$ \\
\hline
\end{tabular}

Fonte: Dados da pesquisa (2019).

A perda da floresta é fator marcante nas respostas dos participantes da pesquisa, e envolvem as queimadas, a extração ilegal de madeiras e o desmatamento, representando juntos 49,3\% nas terras indígenas e 54,3\% nas aldeias dos participantes, ao qual incluí também a extração consentida de madeiras (1,2\%). Nesse sentido, Ferronato \& Nunes (2017), destacam que os indígenas são as maiores vítimas do processo exploratório/predatório, que após o contato com a sociedade não indígena, convivendo com uma nova cultura, "foram ensinados e aliciados por madeireiros a venderem suas riquezas a preços baixíssimos, o que acabou gerando problemas ambientais e sociais, devido à intensa exploração irregular”. Bonavigo (2009), revela também que a extração de madeira das terras indígenas faz com que os madeireiros permaneçam por muito tempo nos limites da área, o que acarreta ao consumo dos recursos que são importantes à sobrevivência dos povos indígenas, que acabam por sofrer também com a redução da caça e da pesca.

Saber os motivos pelos quais os problemas ambientais ocorrem é fundamental para busca de propostas visando sua diminuição ou até mesmo a eliminação. Entre os motivos diagnosticados na pesquisa estão a ambição e ganância do homem $(25,2 \%)$, seguido da falta de fiscalização dos órgãos governamentais $(23,5 \%)$, e da falta de responsabilidade e consciência das pessoas $(21,0 \%)$, conforme pode ser visualizado na Tabela 2 a seguir. 
Tabela 2 - Motivos que fazem com que os problemas ambientais ocorram nas terras e aldeias indígenas. Ji-Paraná, Rondônia, 2019.

\begin{tabular}{lll}
\hline PARÂMETRO & $\begin{array}{l}\text { Frequência } \\
\text { Absoluta }\end{array}$ & $\begin{array}{l}\text { Frequência } \\
\text { Relativa }\end{array}$ \\
\hline $\begin{array}{l}\text { Falta de fiscalização dos órgãos responsáveis, falta de apoio } \\
\text { do governo, falta de orientação e não cumprimento da }\end{array}$ & 28 & $23,5 \%$ \\
legislação & 04 & \\
Falta de fonte de renda nas aldeias (empregos) & 30 & $3,4 \%$ \\
Ambição e ganância do homem & 15 & $25,2 \%$ \\
Falta de conscientização dos próprios indígenas & 25 & $12,6 \%$ \\
Falta de responsabilidade e consciência das pessoas & 16 & $21,0 \%$ \\
Invasão das terras indígenas & 01 & $13,4 \%$ \\
Não respondeu & 119 & $0,8 \%$ \\
\hline
\end{tabular}

Fonte: Dados da pesquisa (2019).

Sobre a conscientização das pessoas em relação ao meio ambiente, Santos et al. (2018), destaca que no Brasil, são inúmeras e atuais as leis que visam proteger o meio ambiente, das quais pode-se citar a Carta Magna de 1998, que em seu artigo 225, descreve que "todos têm direito ao meio ambiente ecologicamente equilibrado, sendo este um bem de uso comum do povo e essencial à sadia qualidade de vida, impondo-se ao Poder Público e à coletividade do dever de defende-lo e preserva-lo para as presentes e futuras gerações”.

Em relação aos responsáveis por causar os problemas ambientais, os resultados da pesquisa apontaram ser os indígenas e lideranças indígenas $(27,4 \%)$, os não-indígenas $(72,0 \%)$ e não respondeu $(0,6 \%)$. Entre os não-indígenas são citados o governo e órgãos competentes (16,7\%), madeireiros (19,6\%), fazendeiros $(14,9 \%)$, garimpeiros $(8,3 \%)$, pescadores $(6,5 \%)$, empresários $(4,8 \%)$ e bolivianos $(1,2)$. O impacto da exploração do homem descomprometido com os fatores ambientais que devem ser respeitados, causa prejuízos as Terras Indígenas, sendo a paralisação dessas atividades ilegais e gananciosas, de suma importância a regeneração da floresta bem como para a manutenção e recuperação da biodiversidade.

Nesse sentido, o que poderia fazer para diminuir ou minimizar esses problemas ambientais? Esse questionamento, apontou para alternativas como, ação dos órgãos governamentais (37,7\%), em relação a equipamentos, ao aumento do número de profissionais, fiscalização, responsabilidade, reuniões com as comunidades indígenas, cumprimento das leis ambientais, criação de novas leis e demarcação dos territórios. Um outro fator que poderia ser adotado é a conscientização da comunidade indígena $(30,2 \%)$, com a realização de reuniões, oficinas, palestras, elaboração de documentos para envio aos governantes e promover o conhecimento junto a escola.

Além desses dois fatores, também foram citados a diminuição dos problemas ambientais e realização de projetos de reflorestamento $(13,8 \%)$, a conscientização dos não-indígenas $(11,3 \%)$, a capacitação de indígenas para fiscalizar e defender seu território e projetos de geração de renda nas aldeias $(7,0 \%)$.

Em relação a esses aspectos, Toledo et al. (2008), por meio da realização de pesquisas em aldeias indígenas, apontam para a importância do desenvolvimento de ações conjuntas na área ambiental e social, incentivando a participação da comunidade local para discutir soluções sobre essas questões. Stumpf et al. (2016), chama a atenção para a importância dos processos educativos socioambientais nas terras indígenas visando contribuir para resolver os problemas ambientais, levando em consideração "um enfoque intercultural, de construção conjunta, escuta de suas demandas e trocas de ideias, com planejamento e execução de ações coletivas”. 


\subsection{Os problemas ambientais e a relação com a educação em ciências}

Você acredita que os problemas ambientais que aconteceu na sua aldeia são estudados na escola? Esse foi o questionamento visando entender se existe uma relação entre os problemas ambientais e o currículo ofertado nas escolas indígenas dos participantes da pesquisa. Foi observado que $84,8 \%$ acredita que sim, $13,4 \%$ não e 1,8\% não responderam ao questionamento. Entre os que acreditam que sim, foi verificado no currículo de qual disciplina esses problemas ambientais diagnosticados poderiam ser trabalhados, sendo a disciplina de ciências e biologia a mais representativa (29,8\%), seguida de geografia $(25,8 \%)$, história $(15,2)$ e língua materna $(10,6 \%)$, entre outras (Figura 3).

Figura 3 - Disciplinas em que os problemas ambientais poderiam ser trabalhados em seus currículos na escola indígena.

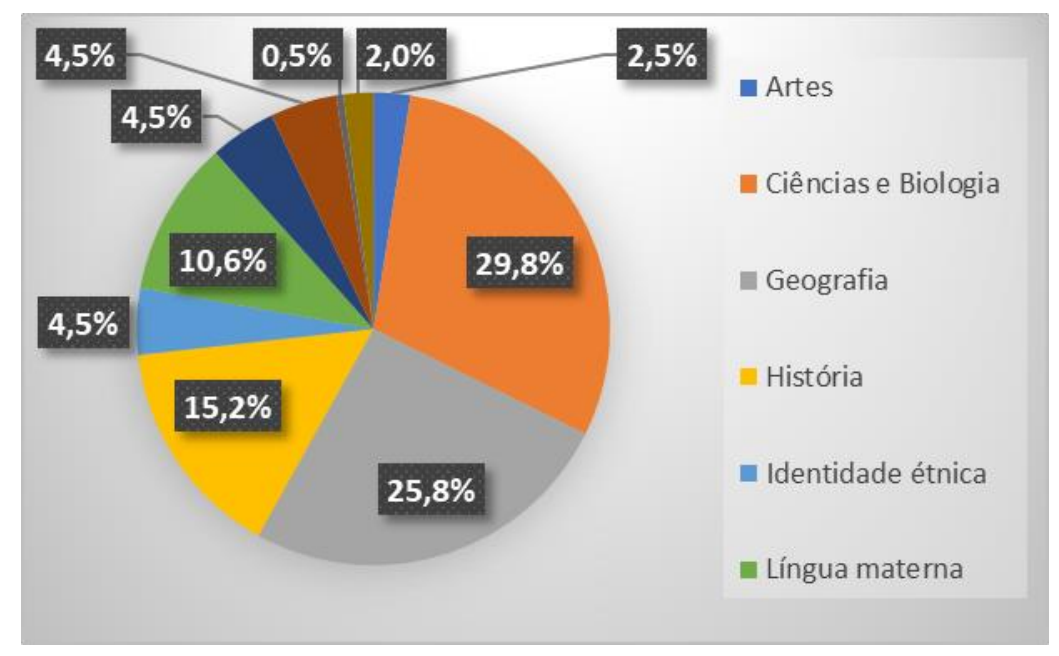

Fonte: Dados da pesquisa (2019).

De acordo com o Rcnei (Referencial Curricular Nacional para as Escolas Indígenas), a área de Ciências "pode contribuir para melhor compreensão das transformações do mundo pelo ser humano na cultura ocidental, por efeito dos avanços dos conhecimentos científicos e tecnológicos e suas aplicações" (Rcnei, 1998, p. 255), já a área de geografia pode "alargar os conhecimentos já existentes, contribuir para a luta contra os preconceitos e em favor do sentimento de pluralidade e apresentar respostas sobre outros povos e sobre fenômenos da natureza" (Rcnei, 1998, p. 228).

No que se refere à disponibilização de informações sobre os problemas ambientais, há de se destacar, segundo Baptista (2010), que "o espaço escolar, e nele o ensino de ciências, muito pode contribuir para alcance desta meta". A demarcação de conhecimentos no ensino de ciências nas comunidades tradicionais, de acordo com Santilli (2002), "se caracterizam por um conjunto de conhecimentos e práticas que são próprios das suas culturas e úteis para as suas sobrevivências".

Sobre a relação dos problemas ambientais e a escola, buscou-se conhecer se durante a vida escolar na aldeia dos participantes, já tinha sido trabalhado pelos professores algum dos problemas ambientais que afetam os povos indígenas. Dos participantes da pesquisa, 6,3\% não estudaram na aldeia, 14,3\% afirmaram que não foi trabalhado, 2,7\% não responderam ao questionamento e $76,8 \%$ destacaram que sim, havia sido trabalhado. Dos que responderam que havia sido trabalhado, apontaram os temas que foram trabalhados (Tabela 3) e quais as estratégias utilizadas pelos professores para abordar tais temas na escola indígena (Figura 4). 
Tabela 3 - Temas trabalhados na escola indígena sobre os problemas ambientais na perspectiva dos participantes da pesquisa. Ji-Paraná, Rondônia, 2019.

\begin{tabular}{lll}
\hline TEMA & $\begin{array}{l}\text { Frequência } \\
\text { Absoluta }\end{array}$ & $\begin{array}{l}\text { Frequência } \\
\text { Relativa }\end{array}$ \\
\hline Diminuição de espécies animais & 03 & $3,2 \%$ \\
Fatores que afetam as terras indígenas (invasão, construção & & \\
de PCH's, queimadas, desmatamento, garimpo, pesca & & \\
ilegal). & 34 & $35,8 \%$ \\
Meio ambiente e preservação & 22 & $23,2 \%$ \\
Poluição & 26 & $27,4 \%$ \\
Saúde (doenças, alcoolismo, plantas medicinais) & 10 & $10,5 \%$ \\
\hline & 95 & $100 \%$ \\
\hline
\end{tabular}

Fonte: Dados da pesquisa (2019).

Entre os temas trabalhados pelos professores nas escolas indígenas dos participantes da pesquisa, os fatores que afetam as terras indígenas, como a invasão, a construção de pequenas centrais hidrelétricas (PCHs), queimadas, desmatamento, garimpo ilegal e pesca ilegal foram os mais citados $(35,8 \%)$,

As estratégias para se trabalhar esses temas nas escolas indígenas pelos professores dos participantes foram palestras $(23,5 \%)$, seguido de explicação oral (19,6\%), cartazes, desenhos, fotografias e vídeos $(17,6 \%)$, entre outros.

Figura 4 - Estratégias de ensino utilizadas pelos professores das escolas indígenas dos participantes da pesquisa para se trabalhar os temas relacionados aos problemas ambientais.

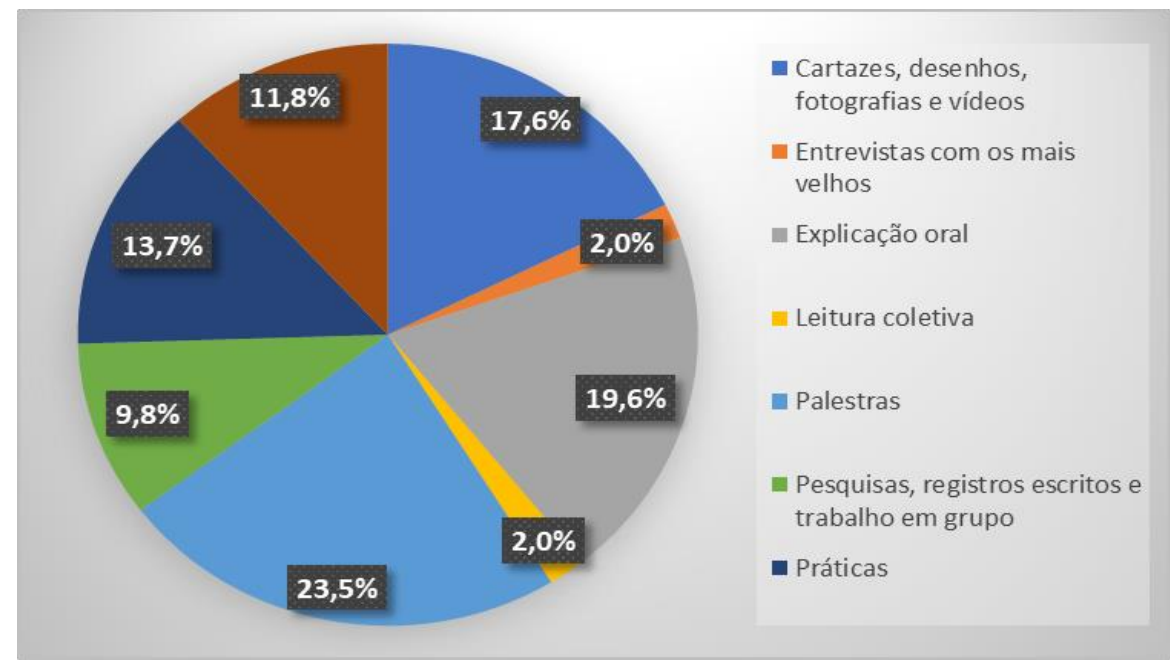

Fonte: Dados da pesquisa (2019).

Os participantes da pesquisa (professores em formação e futuros professores), precisam ter a consciência de que ao diagnosticarem problemas socioambientais em suas aldeias, terão que transpor essas temáticas para o currículo da escola visando compreender e propor soluções conjuntas que ajudem em sua resolução.

Assim, buscou-se conhecer se como professor ou futuro professor, os participantes da pesquisa acreditavam que poderiam trabalhar na escola esses problemas sociais e ambientais que afetam os povos indígenas. Dos participantes, $2,7 \%$ não responderam ao questionamento e 97,3\% disseram que sim. Entre os que disseram que sim, 65,2\% complementaram suas respostas, apontando que poderiam trabalhar com a conscientização dos alunos sobre os problemas (34,2\%), mostrar a realidade, orientar, alertar e oportunizar o conhecimento $(34,2 \%)$, desenvolver atividades na escola $(21,9 \%)$, atividades estas 
relacionadas a oficinais, aulas de campo, palestras, exemplos, práticas, imagens, desenhos e interdisciplinaridade. Também foram citados a realização de pesquisas $(5,5 \%)$ e procura de alternativas para a resolução dos problemas $(4,1 \%)$.

Em relação a forma com que a escola poderia contribuir à resolução dos problemas ambientais que afetam os povos indígenas, os participantes apontaram para a buscar de soluções para os problemas junto aos alunos e comunidade indígena $(35,8 \%)$, a conscientização dos alunos e comunidade (24,6\%), reuniões, palestras e oficinas (20,9\%), entre outros (Tabela 4$)$.

Tabela 4 - Formas com que a escola indígena poderia contribuir na resolução dos problemas ambientais. Ji-Paraná, Rondônia, 2019.

\begin{tabular}{lll}
\hline PROPOSTAS & $\begin{array}{l}\text { Frequência } \\
\text { Absoluta }\end{array}$ & $\begin{array}{l}\text { Frequência } \\
\text { Relativa }\end{array}$ \\
\hline $\begin{array}{l}\text { Buscar soluções para os problemas junto aos alunos e } \\
\text { comunidade indígena }\end{array}$ & 48 & $35,8 \%$ \\
$\begin{array}{l}\text { Conscientização dos alunos e comunidade } \\
\text { Contratação de profissionais capacitados na área }\end{array}$ & 33 & $24,6 \%$ \\
$\begin{array}{l}\text { Criação de uma disciplina específica para discussão } \\
\text { dos temas }\end{array}$ & 01 & $0,7 \%$ \\
$\begin{array}{l}\text { Criação de documentos visando denúncias aos órgãos } \\
\text { públicos }\end{array}$ & 03 & $0,7 \%$ \\
$\begin{array}{l}\text { Inserção dos problemas no currículo da escola } \\
\text { Novas leis e políticas públicas }\end{array}$ & 05 & $2,2 \%$ \\
Produção de material didático de apoio ao professor & 07 & $3,7 \%$ \\
Reuniões, palestras e oficinais & 02 & $5,2 \%$ \\
Valorizaçã̃o étnica, linguística e cultural & 28 & $1,5 \%$ \\
\hline & 06 & $20,9 \%$ \\
\hline
\end{tabular}

Fonte: Dados da pesquisa (2019).

Há uma valorização da escola e centralização das decisões em relação aos acontecimentos da comunidade indígena. Essa informação é compreendida, quando se observa a citação do entrevistado 60, onde afirma que "a escola é um lugar central para que a comunidade busque diálogo de qual forma enfrentamos com os problemas e os professores são lideranças que tem mais conhecimento fora da comunidade e isso eles colocam em prática para o ensino dentro da escola e principalmente na comunidade.

Nesse sentido, Breves et al. (2013), destaca que os conhecimentos tradicionais dos povos indígenas e seus processos próprios de aprendizagem só fazem sentido e só podem ser compreendidas no contexto, isto é, nas especificidades históricas e culturais em que são geradas, à luz e em articulação com o momento histórico da sua produção.

Em contexto interétnico e intercultural, os povos tradicionais vêm demonstrando capacidade de resistência, e se engajando em movimentos e ações destinados à recuperação de sua autonomia e autodeterminação, para incorporar conhecimentos e tecnologias do mundo dos não índios, afinando-as com o seu modo de ser e viver, com sua forma de organização política, social e econômica (Breves et al., 2013).

\section{Considerações Finais}

Tendo em vista o empoderamento dos povos indígenas na Amazônia e sua autonomia na tomada de decisões em relação a construção do futuro, a escola indígena bem como a educação em ciências, tem papel fundamental visando a 
construção de pontes entre os saberes tradicionais dos povos indígenas, adquiridos ao longo de gerações, por meio do contato direto com a natureza e os saberes científicos da sociedade ocidental.

Entende-se por empoderamento, o modo com que um determinado grupo, por suas experiências e construção da cultura, se empenha na obtenção do poder político, que para Paulo Freire, indica "um processo político das classes dominadas que buscam libertar-se da dominação e que veem na educação uma frente de luta pela libertação" (Freire, 1994). O empoderamento pode ser entendido também, como fator que permite com que os alunos das escolas indígenas possam interrogar e apropriar dos aspectos ambientais, se apropriando de conhecimentos, por meio de conteúdos na disciplina de ciências, possibilitando transformações tanto individuais quanto coletivas necessárias para o grupo indígena.

Há necessidade de diagnóstico dos problemas ambientais que interferem no cotidiano das comunidades indígenas e transpor a discussão sobre esses problemas para o currículo da escola indígena. Nesse sentido, não é preciso deixar a cultura e os conhecimentos tradicionais de lado, é necessário sim, fazer com que a sociedade, cada vez mais gananciosa, entenda o seu papel no equilíbrio do meio ambiente, se fazendo como parte integrante dele. Papel esse compreendido pelos povos indígenas, que os fazem parte do meio em que vivem.

Se por um momento, a disciplina de ciências sozinha, não seja capaz ainda desse fortalecimento, é possível que por meio de planejamento e da formação dos novos professores indígenas, que essas visões sobre os problemas ambientais possam refletir no currículo das escolas indígenas. Afinal, as escolas indígenas são consideradas fortes aliadas na busca da autonomia e da afirmação da sua identidade cultural.

Há de se considerar que esse trabalho não encerra aqui. Existe muito a se pesquisar visando compreender como as questões ambientais que afetam os povos indígenas na Amazônia podem ser inseridas na educação em ciências, mediante a prática pedagógica dos futuros professores indígenas que irão atuar nas escolas de suas aldeias.

\section{Referências}

Abi-Eçab, P. C. (2011). Principais ameaças ao meio ambiente em terras indígenas. Planeta Amazônia, 3, 1-17.

Baptista, G. C. S. (2010). Importância da demarcação de saberes no ensino de ciências para as sociedades tradicionais. Ciência \& Educação, $16(3), 679-694$.

Bencze, J. L. \& Sperling, E. R. (2012). Student-teachers as advocates for student-led researchinformed socioscientific activism. Canadian Journal of Science, $12(1), 62-85$.

Bonavigo, P. H. (2009). Levantamento da mastofauna de médio e grande porte da terra indígena sete de setembro - etnia Suruí, RO. Acta Brasil, 12(2), 25-43.

Breves, N. S. P., \& Mota, D. S. M. \& Mubarac Sobrinho, R. S. (2013). Reflexões sobre as concepções de ciências e conhecimento/saberes tradicionais indígenas dos Omágua/Kambeba. Revista Amazônica de Ensino de Ciências, 6(11), 123-136.

Carneiro Filho, A. (2009). Atlas de pressões e ameaças às terras indígenas na Amazônia brasileira. São Paulo: Instituto Socioambiental.

Ferronato, M. L. \& Nunes, R. O. (2017). A exploração ilegal de madeiras na Terra Indígena Sete de Setembro, Cacoal - RO. Revista Científica FACIMED, 4(2), 45-56.

Freire, P. (1994). Pedagogia do Oprimido. Rio de Janeiro: Paz e Terra.

Hodson, D. (1998). Teaching and learnig Science: towards a perrsonalized approach. Buckingham: Open Univestity Press.

Nascimento, M. C., Soares, V. P., Ribeiro, C. A. A. S. \& Silva, E. (2006). Mapeamento dos fragmentos de vegetação floresta nativa da bacia hidrográfica do rio Alegre, Espírito Santo, a partir de imagens de satélite Ikonos II. Revista Árvore, 30(3), 389-398.

Pereira, A. S., Shitsuka, D. M., Parreira, F. J. \& Shitsuka, R. (2018). Metodologia da Pesquisa Científica. Santa Maria, RS: UFSM, NTE.

Rcnei. Referencial curricular nacional para as escolas indígenas. (1998). Ministério da Educação e do Desporto, Secretaria de Educação Fundamental, Brasília.

Reis, P. G. R. (2013). Da discussão à ação sociopolítica sobre controvérsias sócio-científicas: uma questão de cidadania. Ensino de Ciências e Tecnologia em Revista, 3(1).

Reis, P. G. R. (2004). Controvérsias sócio-científicas: discutir ou não discutir? percursos de aprendizagem na disciplina de ciências da terra e da vida. Tese (Doutoramento em Educação) - Departamento de Educação, Faculdade de Ciências, Universidade de Lisboa, Lisboa. 
Research, Society and Development, v. 10, n. 1, e8110111457, 2021

(CC BY 4.0) | ISSN 2525-3409 | DOI: http://dx.doi.org/10.33448/rsd-v10i1.11457

Reis, P. G. R. (1997). A promoção do pensamento através da discussão dos novos avanços na área de biotecnologia e da genética. Dissertação (Mestrado em Educação) - Departamento de Educação, Faculdade de Ciências, Universidade de Lisboa, Lisboa.

Santilli, J. (2002). A biodiversidade das comunidades tradicionais. In: Besunsan, N. (Org.). Seria melhor ladrilhar? Biodiversidade como, para que, por quê. Brasília: Editora Universidade de Brasília, Instituto Socioambiental.

Santos, C. C. O., Zeitune, D. P. \& Santos, J. L. M. (2018). A não fiscalização dos órgãos governamentais e a trajetória da Samarco. Lexcult, $2(1)$, 110-129.

Soares, J. A. B. \& Pereira, J. G. (2015). Diagnóstico ambiental na reserva indígena de Dourados, MS. VI Congresso Brasileiro de Gestão Ambiental, Porto Alegre, RS.

Stumpf, B. O., Wolf, D. R. \& Bergamaschi, M. A. (2016). Reflexões interculturais sobre educação ambiental indígena. Revista Eletrônica do Mestrado em Educação Ambiental, 33(2), 247-267.

Toledo, R. F., Giatti, L. L. \& Pelicioni, M. C. F. (2008). Urbanidade rural, território e sustentabilidade: relações de contato em uma comunidade indígena no noroeste amazônico. Ambiente \& Sociedade, 12(1), 173-188. 